Folia phoniat. 1971;23:261

\title{
Soins médicaux des acteurs et des chanteurs
}

G.

\section{Cornut}

Lyon

Adresse de l'auteur: G. Cornut, 45, rue République, Lyon $2^{\mathrm{e}}$ (France)

A Lyon, existe un Conservatoire Regional de Musique et d'Art drama-tique comprenant, en particulier, 2 classes de chant, une classe d'opérette, une classe d'art lyrique, une classe d'art dramatique et une classe de diction. A la demande du Directeur du Conservatoire, a été créé un poste officiel de «Médecin-Phoniatre du Conservatoire», reconnu et rémunéré par la Municipalité, poste que j'occupe depuis 1965. Le role du Médecin-Phonia-tre dans le Conservatoire est triple:

Faire partie du Jury du Concours d'Entrée et du Concours de Fin d'Année du Conservatoire. Le médecin a done la possibilité de donner son avis sur les défauts vocaux qui ont pu être remarqués au cours de $\Gamma$ exécution.

Faire passer à tous les élèves de chant un examen annuel prophylac-tique comprenant un examen détaillé de $\Gamma$ appareil phonateur et une analyse acoustique de la voix à $\Gamma$ aide du Sonagraph. Les résultats de cet examen sont communiques éventuellement au Professeur de Chant et peuvent être ainsi utilises pour résoudre certains problèmes vocaux particuliers.

Presenter aux élèves quelques exposes annuels destines à leur donner des informations pratiques sur le fonctionnement de Гappareil vocal. 